\title{
$\mathfrak{\Im} \mathfrak{n} \mathfrak{h} \mathfrak{a} \mathfrak{l} \mathbf{t}$
}

Einleitung

Eeite $\mathrm{V}-\mathrm{XIII}$

\section{PrMgemeiner Teil.}

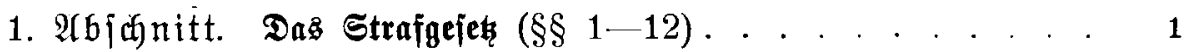

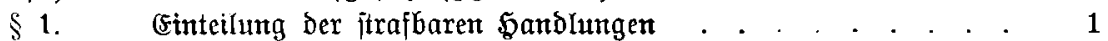

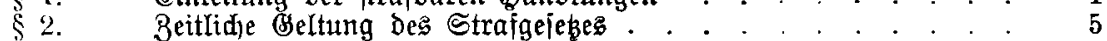

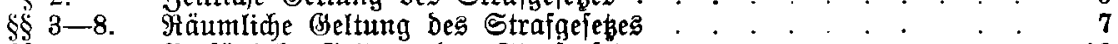

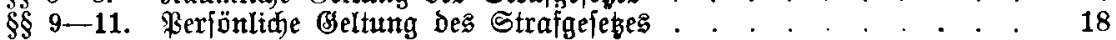

§12. Spradgebraud Dieję Brefekez . . . . . . . . . . . . . . . . . . 19

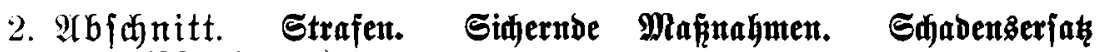

$(\S \S 13-57)$. . . . . . . . . . . . . . . . . . . . 28

\$13. Todesitrafe . . . . . . . . . . . . . . . . . . . 23

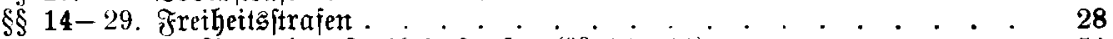

Anten Der Freihetisftrafen $(\S \S 14-20) \quad$. . . . . . . . 51

Dauer uno Anwendungägebiet Der Freiheitştrafen . . . . 54

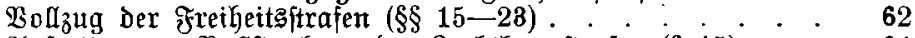

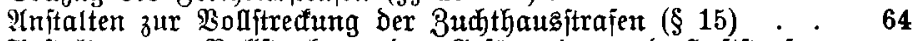

Injtalten $z^{\mathfrak{u r}}$ Bolffrectung ber Befängni $(\$ \S 17,20$ $2 \mathfrak{b} ; .1)$

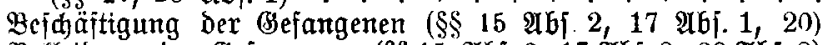

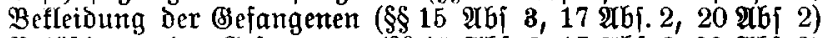

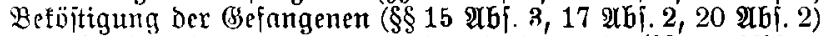

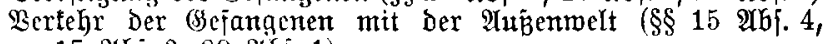
17 ibj. 3, 20 ibj. 1 )

Trennung Der betangenen $(\$ \$ 21,22)$

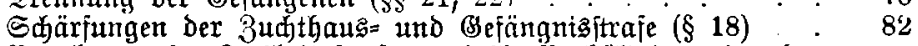

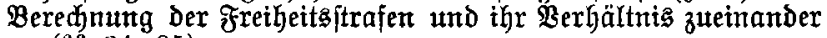
$(\S \S 24,25)$. . . 89

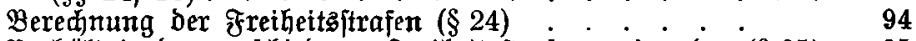

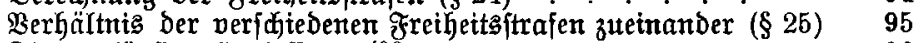

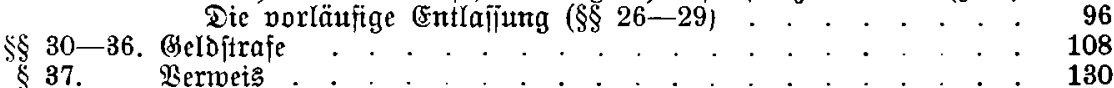

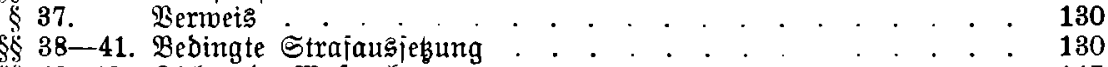

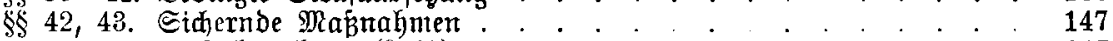

Mrbeitahaus $(\$ 42)$. . . . . . . . . . . . . 147

Birtahaußnerbot. Unterbringung in eine Trinferheilanftalt $(\$ 43)$. . . . . . . . . . . . . . . . . 157

$\S$ \$4-49. Ehrentitrajen . . . . . . . . . . . . . . . . . . 162

Folgen Der Budfthausjtrafe $(\$ 44)$. . . . . . . . . . . 163

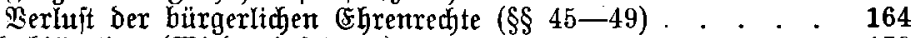

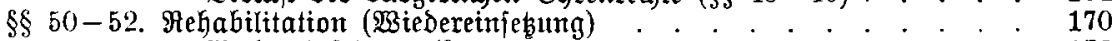

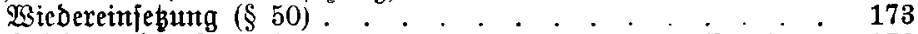

Qöichung Der Beitrafung in Dem Strafregifter $\mathfrak{u}[$ m. (\$ 51$): 176$

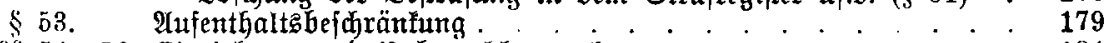

$\$ 54-56$. (Finziehung und unbraudb barmadjung . . . . . . . . . . 184

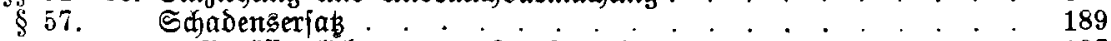

Seröfientlidung von 厄trajurteilen. 


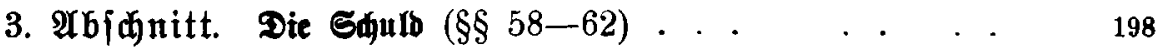

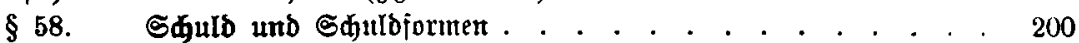

\$5. \$oriak. Abftat . . . . . . . . . . . . . . . . . . . . 202

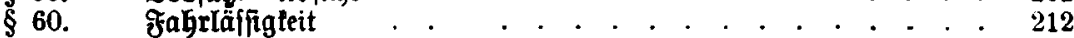

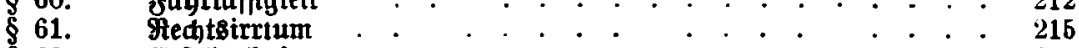

§ 62. Crfolgghajtung . . . . . . . . . . . . . . . . . . . . 220

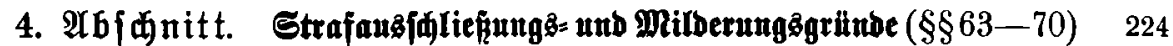

§ 63. Getjtige Mängel . . . . . . . . . . . . . . . . 225

unzuredynungsfähigfeit (âf. 1) . . . . . . . . . . . 225

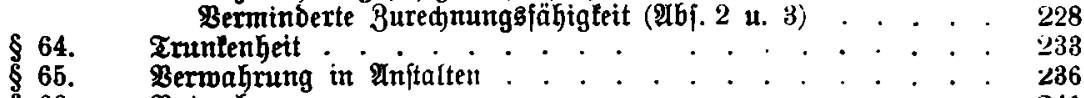

\$ 66. Rotwehr . . . . . . . . . . . . . . . . . . . 241

\$67. Rotftand . . . . . . . . . . . . . . . . 246

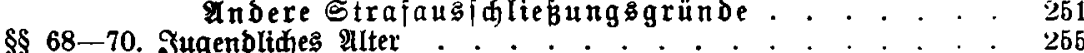

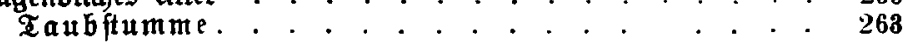

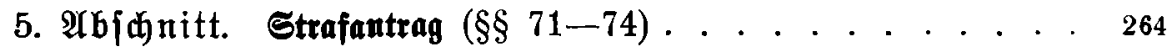

§71. §rijt . . . . . . . . . . . . . . . . . . . . 268

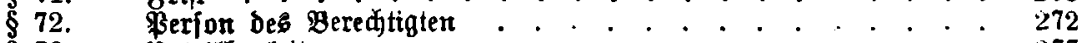

\$ 73. Unteilbarleit . . . . . . . . . . . . . . . . . . . 277

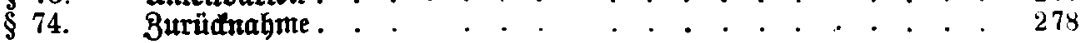

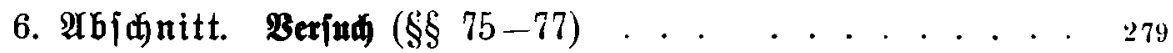

\$7. Begriff. IIntauglidie Dittel ujm. . . . . . . . . . . . . 281

§6. Peftrafung . . . . . . . . . . . . . . . . . . . . . 292

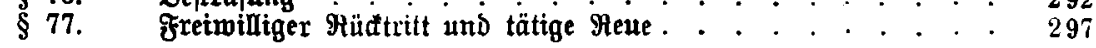

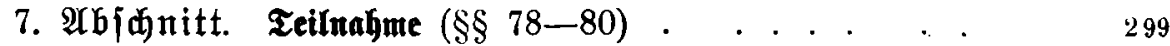

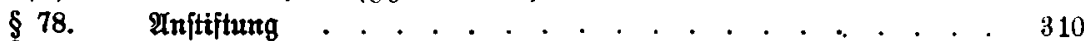

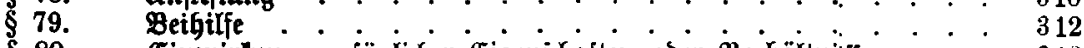

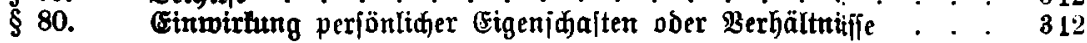

8. $\mathfrak{A b}\lceil$ d nitt. Strafbeme

\$ 81. Strafbemefiung . . . . . . . . . . . . . . . . . . . 313

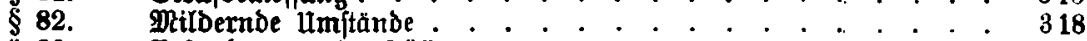

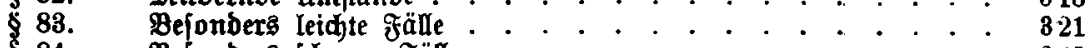

84. Bejonbers jđunere fällle. . . . . . . . . . . . . 326

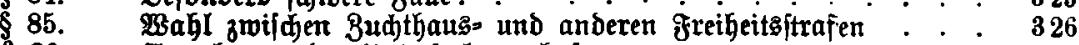

\$ 86. Inrewnung ber llnterfudutgshaft . . . . . . . . . . . . 327

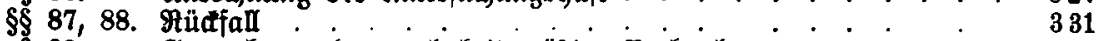

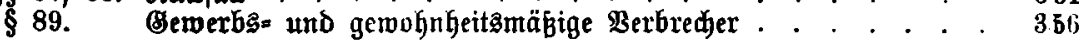

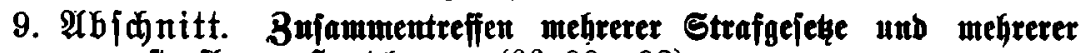

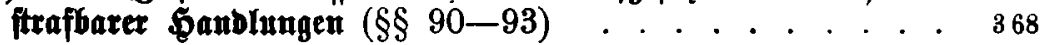

\$90. $3 \mathfrak{u}$ ammentreffer mehrerer Strajgejeze . . . . . . . . . . . 371

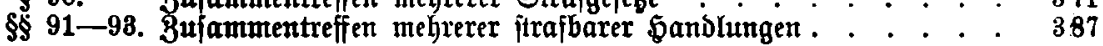

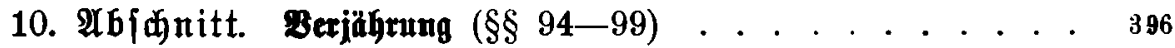

§ 94. Berjäbrung Der ftrafbaren \$andungen . . . . . . . . . . 398

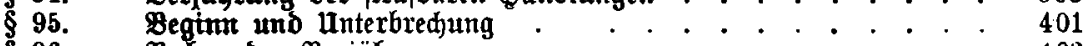

\$ 96. Muhen Der Beriährung . . . . . . . . . . . . . . . 403

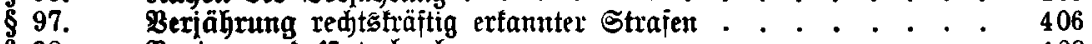

\$ 98. Beginn und unterbredung . . . . . . . . . . . . . 408

$\S 99$. Muhen oer Berjährung . . . . . . . . . . . . . . . 409 